\title{
SSynthesis
}

International Scientific Conference of IT and Business-Related Research

\section{PODRŠKA MALIM I SREDNJIM PREDUZEĆIMA U SRBIJI OD STRANE EVROPSKE BANKE ZA OBNOVU I RAZVOJ}

\author{
SUPPORT OF THE EUROPEAN BANK FOR RECONSTRUCTION AND DEVELOPMENT TO SMALL \\ AND MEDIUM-SIZED ENTERPRISES IN SERBIA
}

\author{
Nino Vesković, Aleksandra Bakrač \\ Poslovni fakultet u Beogradu, Univerzitet Singidunum, Danijelova 32, Beograd, Srbija
}

\begin{abstract}
:
Evropska banka za obnovu i razvoj (The European Bank for Reconstruction and Development EBRD) pruža podršku malim i srednjim preduzećima (MSP) u Republici Srbiji (RS) u vidu finansiranja, kreditiranja, pružanja savetodavnih usluga, kao i sprovođenjem određenih programa. Aktivnosti se sprovode i van Beograda (77\%) naročito putem bankarskog kreditiranja. Pružanjem podrške malim i srednjim preduzećima (MSP) u Srbiji, EBRD zapravo pomaže preduzećima da se fokusiraju na realne ciljeve i ostvare najbolje moguće rezultate, otvaranjem novih radnih mesta i uvođenjem malih i srednjih preduzeća u Srbiji u evropsko i globalno poslovanje, što pokazuju i ostvareni rezultati. Na osnovu dobijenih rezultata, može se videti da $68 \%$ MSP posluje sa poboljšanom produktivnošću, dok $41 \%$ malih i srednji preduzeća igra presudnu ulogu u procesu otvaranja novih radnih mesta.
\end{abstract}

\section{Key words:}

podrška, realni ciljevi, stopa zaposlenosti, rast i razvoj

\section{UVOD}

Kroz podršku Evropske banke za obnovu i razvoj (European Bank for Reconstruction and Development EBRD) malim i srednjim preduzećima (MSP) osim programa za poslovanje, pružaju se i poslovni saveti za pomoć putem kojih se MSP razvijaju, uspešno, i postaju istinski katalizatori kako lokalnih ekonomija, tako i onih u regionu. Uspešan sektor MSP jeste krucijalan za zdravu tržišnu ekonomiju, ali sama MSP često ne mogu da odgovore na finansijske izazove sa kojima se suočavaju. MSP treba da budu upoznata i sa načinom na koji bi mogla da poboljšaju svoj rad i ostvare benefite. EBRD nudi pomoć vezanu za knowhow, koji pomaže funkcionisanje poslovanja, marketinga, strategija, upravljanja kvalitetom, energetske efikasnosti, finansijsko upravljanje i slično (EBRD, 2015).

Osnovna hipoteza koja je postavljena ovim istraživanjem polazi od toga da se, uz pomoć EBRD-a mala i srednja preduzeća nalaze u prilici da se fokusiraju na ciljeve koji su realni i da ostvare najbolje moguće rezultate, poboljšavajući konkurentnost i produktivnost privatnog sektora i njihove performanse, otvarajući nova radna mesta i uvodeći srpska MSP u evropsko i globalno poslovanje. Osim toga, stručnjaci EBRD, godinu dana po okončanju svakog projekta, obilaze klijenta i mere promene koje su se dogodile u poslovanju.

\section{Apstrakt:}

The European Bank for Reconstruction and Development (EBRD) provides support to small and medium-sized enterprises (SMEs) in the Republic of Serbia (RS) in the form of funding, lending, provision of consulting services and implementing specific programs. Activities are carried out outside Belgrade (77\%), especially through bank lending. By providing support to SMEs in Serbia, EBRD actually helps them to focus on setting realistic goals and achieve the best possible results, thereby creating new job openings and introducing Serbian SMEs in the European and global economies, as shown by the results achieved. According to the results obtained, $68 \%$ of SMEs operate with enhanced productivity, while $41 \%$ of SMEs plays a crucial role in creation of new job vacancies.

Ključne reči:

support, realistic goals, employment rate, growth and development.

\section{REZULTATI}

Od početka delovanja EBRD u Srbiji 2001. godine, ova institucija je svojim savetima pomogla više od 550 preduzeća, zahvaljujući sredstvima prikupljenim iz Austrije, Kanade, Danske, Evropske unije, od Akcionara Posebnog fonda EBRD, iz Grčke, Italije, Japana, Luksemburga, Holandije, Švedske, Fonda saradnje Tajvan - EBRD i Velike Britanije. EBRD podržava preduzeća iz mnogih grana industrije, poput prehrambene, trgovine na veliko i malo, distribucije, građevinarstva i inženjeringa. EBRD se ne fokusira samo na projekte u glavnom gradu, već se $77 \%$ projekata ostvaruje van Beograda (EBRD, 2015).

Stručnjaci EBRD u Srbiji zaduženi su za pružanje podrške MSP povezivanjem klijenata sa lokalnim i međunarodnim konsultantima, izvršavanjem transformacije ogromnog dela biznisa i uvođenjem u globalno poslovanje, čime se dokazuje osnovna hipoteza koja je definisana u uvodnom delu rada. Bilo da je u pitanju kreiranje novog sajta, sistema upravljanja kvalitetom, marketing strategija ili čak potpuno nova struktura upravljanja, stručnjaci poslati od strane EBRD su u mogućnosti da pruže pomoć kako bi se definisao najbolji projekat koji odgovara potrebama MSP. Koristeći dugogodišnje iskustvo navedeni stručnjaci su do samog kraja posvećeni projektu koji treba da pokaže do 
kraja da ostvaruje najbolje rezultate (EBRD, 2015), što ponovo dokazuje tvrdnje navedene u osnovnoj hipotezi.

Instrument za pretprisutnu pomoć (IPA) finansira "Podršku za razvoj MSP u Srbiji” tokom perioda koji traje 36 meseci, odnosno do juna 2016. godine. Ovaj Program se bazira na učešću MSP u troškovima, što potencijalne klijente obavezuje na uplatu dela projektnih troškova u iznosu $25-75 \%$ za one projekte u koje su uključeni domaći konsultanti. Projekti većeg obima, od kojih se očekuje da će uključiti podršku međunarodnih konsultanata, pretpostavljaju učešće klijenta od $10 \%$ za prvi i $50 \%$ troškova za drugi projekat (Nacionalna agencija za regionalni razvoj)

Kao ključni izazov EBRD u podstreku za razvoj MSP je postavila širenje bankarskog kreditiranja naročito van Beograda i ažurniju pokrivenost koja se odnosi na informacione tehnologije što bi, automatski, dovelo do poboljšanja tehničkog dela posla vezano za zahteve koji se odnose na bankarsko kreditiranje. Potencijal koji poseduju MSP postao je vidljiv bankama i mnoge su stoga, otvorile posebne sektore za odnos sa MSP, ali je finansiranje bilo ograničeno u malim gradovima, a kreditiranje MSP je procenjeno na $38 \%$ kreditnog portfolia banaka, a učešće MSP u ostvarenoj dodatnoj vrednosti iznosi 50,1\%. Osim toga, MSP su zaslužna za otvaranje 59,7\% radnih mesta na teritoriji Srbije, po istraživanjima obavljenim 2012. godine (EBRD, 2014), što je prikazano na slici 1.

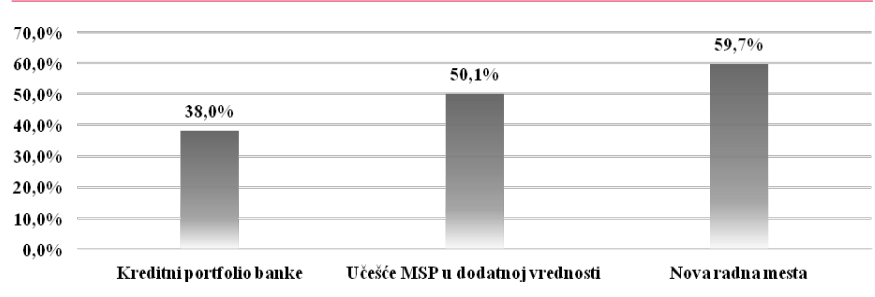

Slika 1. Osnov za širenje bankarskog kreditiranja MSP za EBRD

Izvor: autori, na osnovu navedenih podataka u radu

Ipak, MSP ne pokazuju zadovoljavajući nivo razvoja u odnosu na zemlje članice Evropske unije, i to naročito u oblasti internacionalizacije, inovacija i stručnosti. Ono što predstavlja prednost i olakšavajuću okolnost u Srbiji je činjenica što sektor MSP poseduje bolji pristup finansiranju nego prosek EU. Uslovi koje je neophodno ispuniti, a vezani su za obezbeđenje kredita namenjenih privredi (realne kamatne stope u domaćoj valuti) su ozbiljni i rizični, budući da je, u periodu od 2006. godine, došlo do povećanja devizne izloženosti MSP. Uprkos činjenici da se kreditni informacioni sistem znatno unapredio u smislu pokrivenosti i efikasnosti, kreditne informacije se mogu dobiti samo od finansijskih institucija. Ipak, katastarski sistem je unapređen 2011. godine što je ubrzalo postupak uknjiženja. Narodna Skupština Republike Srbije (RS) je 2012. godine odobrila otvaranje državne razvojne banke, koja će imati posebno odeljenje za poslovanje sa MSP (EBRD, 2014).

Primetno je da je 68\% korisnika usluga EBRD pokazalo poboljšano poslovanje, kako u smislu povećanog prometa tako i u pogledu povećane produktivnosti. Mogućnosti za otvaranje novih radnih mesta pružilo je $41 \%$ preduzeća, spoljno finansiranje rasta svojih preduzeća obezbedilo je 18\% klijenata (EBRD, 2014). Navedeni podaci ukazuju vidan napredak u poslovanju MSP - korisnika usluga koje pruža EBRD, a naročito zbog korišćenja finansijske pomoći, poboljšanih usluga korišćenja kredita, savetodavne pomoći i poboljšanja funkcionisanja katastarskog sistema. Na ovaj način ostvareni su benefiti i dokazana postavljena osnovna hipoteza.

Shodno dokumentima koji su korišćeni i podacima koji su predstavljeni, a bazirano na izveštajima stručnjaka u roku od godinu dana od početka projekta, ostvareni su sledeći rezultati, koji su u skladu sa navedenom postavljenom hipotezom, a predstavljeni su na slici 2.

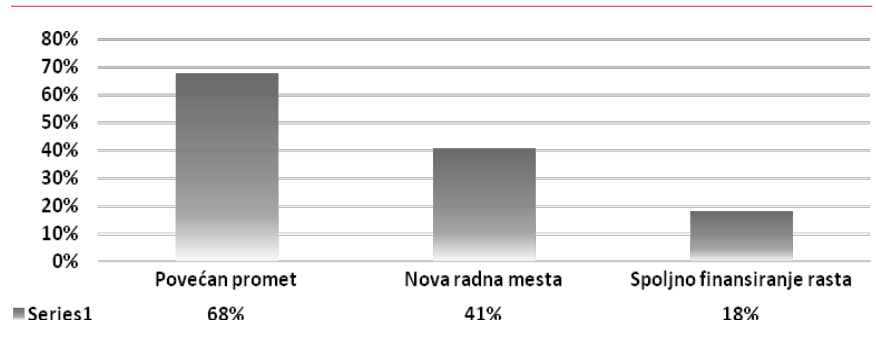

Slika 2. Ostvareni rezultati aktivnosti EBRD vezano za sektor MSP

Izvor: autori, na osnovu navedenih podataka u radu

\section{REZIME}

$\mathrm{Na}$ osnovu predstavljenih rezultata vezanih za poboljšano poslovanje klijenata od $68 \%$, za otvaranje novih radnih mesta zaslužno je $41 \%$ MSP, $68 \%$ je aktivno sa poboljšanom produktivnošću, a 18\% klijenata je obezbedilo spoljno finansiranje svoga rasta. Stoga, potpuno je evidentno da je dokazana postavljena hipoteza po kojoj EBRD pruža neohodnu pomoć i podršku razvoju MSP u Srbiji, kojom se poboljšava konkurentnost i produktivnost privatnog sektora i njihovih performansi, odnosno pomaže fokusiranje na realne ciljeve i ostvarivanje najboljih mogućih rezultata, time otvarajući nova radna mesta i uvodeći srpska MSP u evropsko i globalno poslovanje.

\section{LITERATURA}

EBRD. (2015). Grow your business in Serbia. Preuzeto 12. Marta 2015. sa http://www.ebrd.com/work-with-us/advice-forsmall-businesses/serbia.html

EBRD. (2014). Strategija za Srbiju. Preuzeto 12. Marta 2015. sa http://www.ebrd.com/downloads/country/strategy/Strategija_za_Srbiju_28_01_2014.pdf

Nacionalna agencija za regionalni razvoj. (2015). Podrška za razvoj MSP u Srbiji. Preuzeto 12. Marta 2015. sa http://narr. gov.rs/index.php/Info/Konkursi/Podrshka-razvoj-MSP-uSrbiji 